\title{
İnşaat Asansörleri İstikamet Makaralarında Kullanılan Farklı Çelik Malzemelerin Aşınmalarının İncelenmesi
}

\author{
Ünal KILINÇ1®), Şevki Yılmaz GÜVEN2® \\ 1,2Süleyman Demirel Üniversitesi, Mühendislik Fakültesi, Makine Mühendisliği Bölümü, 32040, Isparta, Türkiye
}

(Alınış / Received: 20.01.2020, Kabul / Accepted: 06.01.2021, Online Yayınlanma / Published Online: 15.04.2021)

Anahtar Kelimeler

Aşınma,

Yorulma aşınması,

Makara,

İnşaat asansörü
Özet: Bu çalışmada, inşaat yük asansörlerinin istikamet makaralarında farklı çelik malzemelerin kullanılmasının, makara üzerinde oluşan aşınma miktarına etkisinin incelenmesi amaçlanmıştır. Çalışmada, inşaat yük asansörlerinin istikamet makaralarında kullanılacak en uygun malzemeyi seçmek hedeflenmiştir. İstikamet makaraları, SAE (AISI) 4140, SAE (AISI) 8620 ve SAE (AISI) 1040 çeliklerinden imal edilerek yağsız kuru sürtünme şartlarında aşınmaya maruz bırakılmıştır. İmal edilen istikamet makaraları farklı noktasal temas sayılarında test edilmiștir. Aşınan yüzeyler ve aşınma partikülleri fiziksel olarak incelenmiştir ve aşınma mekanizması tespit edilmiştir. Bir hassas terazi yardımıyla aşınmadan kaynaklanan ağırlık kaybı ölçülmüştür. Ölçülen ağırlık miktarları, çelikler arasında karșılaștırılmıștır. Sonuç olarak, inșaat yük asansörlerinde kullanılan istikamet makaralarında aşınma mekanizması, yorulma aşınması olarak saptanmıştır. Sertlik değerlerinin yakın olmasına rağmen, aşınma miktarları farklı bulunmuştur.

\section{Investigation of The Wear of Different Steel Materials Used on the Direction Rollers of Construction Hoists}

Keywords

Wear,

Pitting wear,

Roller,

Construction hoist

\begin{abstract}
In this research, it is aimed to investigate the effect of the use of different steel materials on the direction pulleys of construction hoists on the amount of wear on the pulley. In this study, it is aimed to select the most suitable material to be used in the direction pulleys of construction hoists. Direction rollers are manufactured from SAE (AISI) 4140, SAE (AISI) 8620 and SAE (AISI) 1040 steels and exposed to wear in dry oil-free friction conditions. The direction rollers manufactured have been tested at different point contact numbers. Abrasive surfaces and wear particles were physically examined and the wear mechanism was determined. Weight loss due to wear was measured with the aid of a precision scale. The measured weights are compared between steels. As a result, the wear mechanism in the direction rollers used in construction hoists has been determined as fatigue wear. Although the hardness values are close, the wearing amounts were found different.
\end{abstract}

\section{Giriş}

İnşaat asansörleri istikamet makaraları, inşaat asansörlerinin önemli parçalarından birisidir. Asansörün istenilen yönde raydan ayrılmadan ilerlemesi ve üzerindeki personeli ve yükü güvenli bir şekilde taşıyabilmesi için istikamet makaralarının performansı önemli bir kriterdir.

İnşaat sektörü ülkenin önde gelen sektörlerinden birisidir. Her sektörde olduğu gibi bu sektörde de güvenlik ve hız çok önemli bir faktördür. İnşaat çalışmalarının güvenli ve hızlı bir şekilde ilerleyebilmesi için birçok makineye ihtiyaç vardır. $\mathrm{Bu}$ makinelerden biri de inşaat yük asansörleridir. Personellerin güvenli bir şekilde seyredebilmesinde ve inşaat için kullanılan malzemelerin hızlı ve güvenli bir şekilde taşınabilmesinde bu tür asansörlerin kullanılması kaçınılmazdır.

Günümüzde yük asansörleri sadece inşaat sektöründe kullanılmakla kalmayıp termik santrallerin bacalarında, fabrikalarda, köprü ayakları ve depo gibi birçok alanda kullanılmaktadır. Giderek kullanımı artan bu asansörlerin deformasyona maruz kalan ekipmanlarının başında istikamet makaraları 
gelmektedir. Üretici firmaların makara malzeme seçiminde yanlış karar vermesi, makaraların periyodik muayeneden önce deformasyona uğramasına sebep olmaktadır. $\mathrm{Bu}$ durum da periyodik muayene maliyetlerinin artması ve daha önemlisi makara deformasyonlarına bağlı olarak asansör kazalarına neden olmaktadır. Asansör kazalarında maliyetler olarak can kayıpları, işgücü kayıpları, tedavi masrafları, ölüm ve iş kaybı tazminatları, yeniden servise alma maliyetleri ile sektöre oluşan güvensizlik ve psikolojik zararlar sayılabilir [1].

$\mathrm{Bu}$ çalışmanın amacı, inşaat yük asansörlerinin istikamet makaralarında farklı çelik malzemelerin kullanılmasının, makara üzerinde oluşturduğu aşınma miktarının incelenmesi ve en uygun makara malzemesinin saptanabilmesidir. Çalışmada, istikamet makarasının aşınma mekanizması tespit edilerek, farklı çeliklerin bu aşınma mekanizması altında ne kadar ağırlık kaybı yaşayacağını tespit etmek amaçlanmaktadır. Bu sayede inşaat yük asansörlerinde kullanılabilecek en uygun makara malzemesi saptanması amaçlanmıştır

Aşınmanın tanımı, en genel haliyle mekanik veya kimyasal etkilerden dolayı malzeme üzerinden istenmeyen partikül kaybıdır. $\mathrm{Bu}$ genel tanımdan farklı olarak aşınmanın birçok farklı tanımı yapılmıştır [2].

Adhezif aşınma; Yüzeylerin birbiri ile teması sonucu adhezyon oluşur [3]. Buna mikro sürtünme kaynağ denir [4]. Hareketin devam etmesiyle mikro sürtünme kaynağı ile bağlanan parçaların bağlantı noktalarında kopmalar meydana gelir.

Abrasif aşınma; İki yüzey arasına dıșarıdan çevresel etkilerle girmiş, eşit sertlikte ya da daha sert yabancı maddelerden kaynaklanan aşınma türüdür [2].

Yorulma ve tabakalı (delaminasyon) aşınma; Adhezif ve Abrasif aşınma mekanizmalarında sürekli bir temas söz konusudur. İki makine elemanının çevrimsel bir teması söz konusu olduğu durumlarda gerçekleşen aşınma türüne Yorulma Așınması adı verilmektedir [3].

Yorulma aşınmasının bir şekli olan tabakalı (delaminasyon) aşınma, yüzey temas noktalarının birbirleri üzerinde sürekli hareketi sonrasında oluşan bir aşınma türüdür [3].

Korozif aşınma; Makine elemanlarının dış ortam ile "kimyasal ve elektrokimyasal" olarak etkileşimlerinden meydana gelen bir aşınma türüdür. [2]. Korozif aşınma kendi başına olabileceği gibi diğer aşınma mekanizmalarıyla birlikte de meydana gelebilir [5]. Ana tanım olarak, bu aşınma mekanizması aşınan malzeme ile aşındıran malzeme (kimyasal madde, reaktif yağlayıcı ya da oksijen gibi) arasındaki bir kimyasal tepkimedir [6].

Erozyon aşınması; Erozyon aşınması, aşındıran partikülün, aşınan malzemelere sürekli olarak çarpasıyla yüzeyden parça koparmasıdır. Aşındıran partikül, sıvı veya katı halde olabilir. Erozyon aşınması aşındıran partikülün ağırlığı, yüzeye çarpma derecesi, yüzeye çarpış hızı ve aşındıran partikül ve aşınan parçanın türüne göre farklılık gösterir [3].

\section{Materyal ve Metot}

$\mathrm{Bu}$ çalıșma, inşaat yük asansörlerinin istikamet makaralarında farklı çelik malzemelerin kullanılmasının makara aşınmasına etkisinin incelenmesi amacı ile yapılmıştır.

Çalışmalarda SAE (AISI) 4140, SAE (AISI) 8620 ve SAE (AISI) 1040 kalitesinde 3 farklı çelik kullanılmıştır. Her çelik türünden 4 er adet olmak üzere toplamda 12 adet makara numuneleri hazırlanmıștır.

Tablo 1.'de numunelerin yapımında kullanılan çeliklerin kimyasal bileşimi, Tablo 2.'de numunenin yapımında kullanılan çeliklerin mekanik özellikleri verilmiştir.

Tablo 1. Çeliklerin Kimyasal Bileșimi (Ağırlıkça) [7, 8, 9].

\begin{tabular}{ccccccc}
\hline ÇELIK & $\% \mathrm{C}$ & $\% \mathrm{Si}$ & $\% \mathrm{Mn}$ & $\% \mathrm{Cr}$ & $\% \mathrm{Mo}$ & $\% \mathrm{Ni}$ \\
\hline SAE 4140 & 0,43 & 0,23 & 0,86 & 0,96 & 0,200 & 0,12 \\
SAE 8620 & 0,23 & 0,31 & 0,85 & 0,55 & 0,22 & 0,53 \\
SAE 1040 & 0,43 & 0,15 & 0,71 & 0,02 & 0,004 & 0,05 \\
\hline
\end{tabular}

Tablo 2. Çeliklerin Mekanik Özellikleri [7, 8, 9].

\begin{tabular}{cccc}
\hline ÇELIK & $\begin{array}{c}\text { Sertlik } \\
\text { (HB) }\end{array}$ & Akma Sınırı & Çekme Sınırı \\
\hline SAE 4140 & 212 & $570-770 \mathrm{~N} / \mathrm{mm}^{2}$ & $850-1000 \mathrm{~N} / \mathrm{mm}^{2}$ \\
SAE 8620 & 217 & $385 \mathrm{~N} / \mathrm{mm}^{2}$ & $530 \mathrm{~N} / \mathrm{mm}^{2}$ \\
SAE 1040 & 220 & $361 \mathrm{~N} / \mathrm{mm}^{2}$ & $600 \mathrm{~N} / \mathrm{mm}^{2}$ \\
\hline
\end{tabular}

\subsection{Test numunelerinin hazırlanması}

Deneysel çalışmada test edilecek olan istikamet makaralarının numunelerinin hazırlanmasında kullanılan yöntem şu aşamalarda ilerlemiştir.

- Bilgisayar ortamında Solidworks 2018 programı kullanılarak istikamet makaralarının 3 boyutlu tasarımı yapılmıștır.

- Tasarıma uygun halde imal edilebilmesi için AYDINLAR MAKINE METAL SAN. VE TIC. LTD. ŞTİ.' den SAE (AISI) 4140, SAE (AISI) 8620 ve SAE (AISI) 1040 kalitesinde 3 farklı çelik, Çapı 85 $\mathrm{mm}$ boyu $42 \mathrm{~mm}$ olarak temin edilmiştir.

- İstikamet makaraları Ankara Ostim'de bulunan FEN-İS MAKINE İNŞAAT TURIZM MÜHENDISLIKK SAN. TİC. LTD. ŞTİ. firması bünyesindeki TOSS Sn 55 marka Torna Tezgahında makara formuna uygun elmas uç kullanılarak imal edilmiştir. 


\subsection{Test cihazının hazırlanması}

İstikamet makaralarının deneyinin yapılacağı test düzeneği bilgisayar ortamında Solidworks 2018 programı kullanılarak 3 boyutlu olarak tasarlanmıştır. Test düzeneğinin boruları ve profilleri kesilmiştir. Önceden hazırlanan kaynak kalıpları yardımıyla, test düzeneği, tasarlanan ölçülerde puntalanmış ve kaynağı tamamlanmıştır. Kaynak işlemi biten test cihazı üzerine Max-Extra 250/500 kg marka-model, 1020 Watt, çıkış devri 35 d/dk motor ve bu motor üzerine 5 modül kremayer dişli ve 18 diş pinyon dişli yerleștirilmiş ve sistemin üretim süreci Şekil 1.'deki gibi tamamlamıştır.

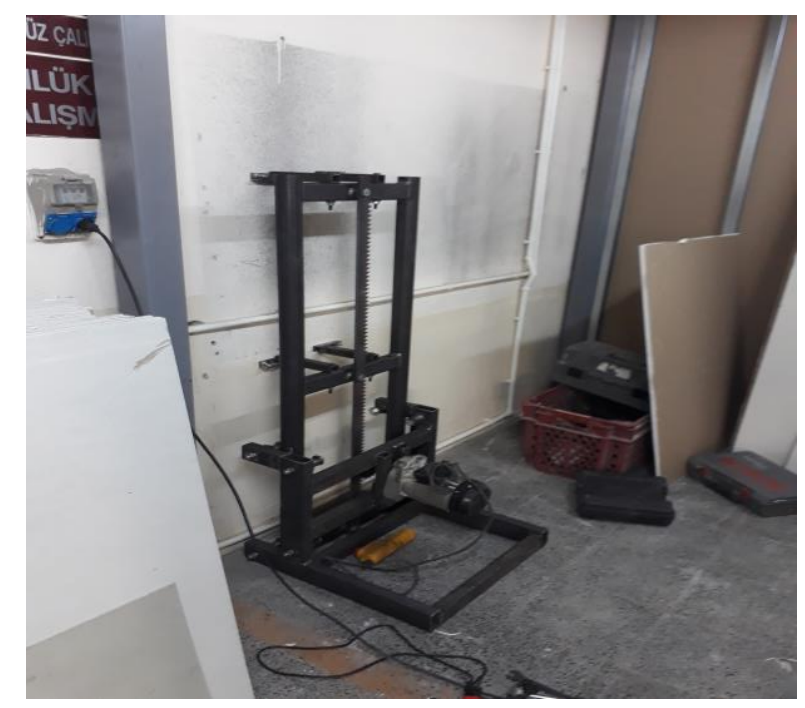

Şekil 1. Test Düzeneği

\subsection{Yöntem}

- Tasarımı yapılıp imal edilen test düzeneği Süleyman Demirel Üniversitesi Mühendislik Fakültesi Makine Mühendisliği Laboratuvarına kurulmuştur.

- Bütün istikamet makaraların aşınma testleri aynı yüzey gerilmesi altında yapılmıştır. İstikamet makaralarının mast ile temas noktasındaki yüzey gerilme miktarı Solidworks 2018 programı yardımı ile sonlu elemanlar metodu kullanılarak tespit edilmiştir. Yüzey gerilme miktarı 5.081 $\mathrm{E}+7 \mathrm{~N} / \mathrm{m}^{2}$ yani $50,81 \mathrm{~N} / \mathrm{mm}^{2}$ dir.

- Tüm makaralar numaralandırılmıștır. 1, 2, 3 ve 4 numaralı makaralar SAE (AISI) 4140, 5, 6, 7 ve 8 numaralı makaralar SAE (AISI) 1040 ve 9, 10, 11 ve 12 numaralı makaralar SAE (AISI) 8620 kalite çelikten yapılan istikamet makaralarıdır.
- Çalışmadan önce tüm makaraların ağırlıkları ölçülmüştür. 1, 5 ve 9 numaralı makaralar sisteme montajlanıp 2500 adet noktasal temas sayısında çalıştırılmıştır. Çalışmadan sonra makaralar titiz bir şekilde sökülmüştür. Sökülen makaralar bir firça yardımıyla metil alkol kullanılarak temizlenmiş, kuruması beklenmiş ve PRECISA LX3200C SCS marka hassas terazi ile ölçülmüştür.

- Bu işlem sırası 2,6 ve 10 numaralı istikamet makaraları için 5000 adet, 3, 7 ve 11 numaralı istikamet makaraları için 7500 adet ve 4,8 ve 12 numaralı istikamet makaraları için 10000 adet noktasal temas sayısında yapılmıştır.

\section{Bulgular}

Deney numuneleri Süleyman Demirel Üniversitesi, Makine Mühendisliği Bölümünde kurulan aşınma test cihazı ile deneylere tabi tutulmuştur. 3 farklı çelik, test cihazı üzerinde 2500, 5000, 7500 ve 10000 adet noktasal temas yapacak șekilde $50.81 \mathrm{~N} / \mathrm{mm}^{2}$ lik yüzey gerilmesi altında yağsız kuru sürtünme şartlarında aşınmaya maruz bırakılmıştır.

3 farklı çeliğin noktasal temas miktarlarına bağlı olarak, çeliklerde meydana gelen aşınma miktarlarının dağılımı Tablo 3.'de gösterilmiştir.

Tablo 3.'deki ağırlık kayıplarından hareketle çeliklerin noktasal temas miktarlarına bağlı olarak ağırlık kayıp miktarlarının değişim grafiği Şekil 2.'de verilmiştir.

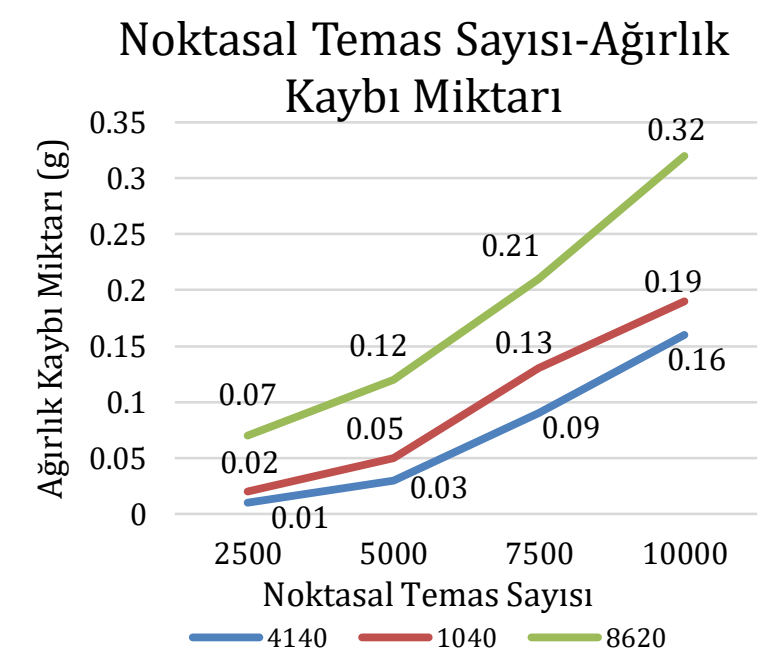

Şekil 2. Çeliklerin ağırlık kaybı değişim grafiği

Tablo 3. Çeliklerin noktasal temas miktarlarına bağlı olarak ağırlık kayıpları

\begin{tabular}{|c|c|c|c|c|c|}
\hline & $\begin{array}{c}2500 \text { Noktasal } \\
\text { Temas Ağırlık Kaybı } \\
\text { Miktarı }\end{array}$ & $\begin{array}{c}5000 \text { Noktasal } \\
\text { Temas Ağırlık Kaybı } \\
\text { Miktarı }\end{array}$ & $\begin{array}{c}7500 \text { Noktasal } \\
\text { Temas Ağırlık Kaybı } \\
\text { Miktarı }\end{array}$ & $\begin{array}{c}10000 \text { Noktasal } \\
\text { Temas Ağırlık Kaybı } \\
\text { Miktarı }\end{array}$ & $\begin{array}{c}\text { Toplam Ağırlık } \\
\text { Kaybı Miktarı }\end{array}$ \\
\hline SAE (AISI) 4140 & 0,01 & 0,03 & 0,09 & 0,16 & 0,29 \\
\hline SAE (AISI) 8620 & 0,07 & 0,12 & 0,21 & 0,32 & 0,72 \\
\hline SAE (AISI) 1040 & 0,02 & 0,05 & 0,13 & 0,19 & 0,39 \\
\hline
\end{tabular}


SAE (AISI) 4140, SAE (AISI) 1040 ve SAE (AISI) 8620 çeliklerinin 10000 noktasal temas sayısının ardından yüzeylerinde meydana gelen aşınmaların görünümleri sırasıyla Şekil 3., Şekil 4. ve Şekil 5.'de belirtilmiştir.

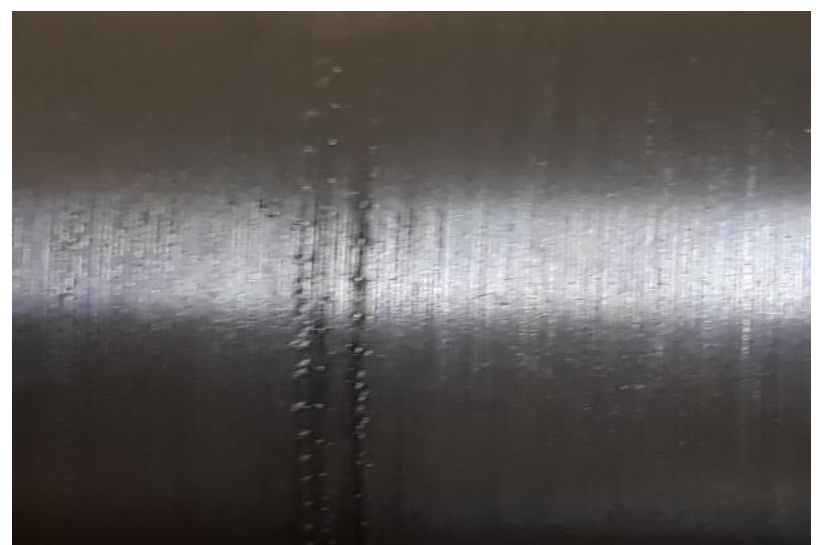

Şekil 3. SAE (AISI) 4140 çeliğinin 10000 noktasal temas sonucunda yüzey görünümü

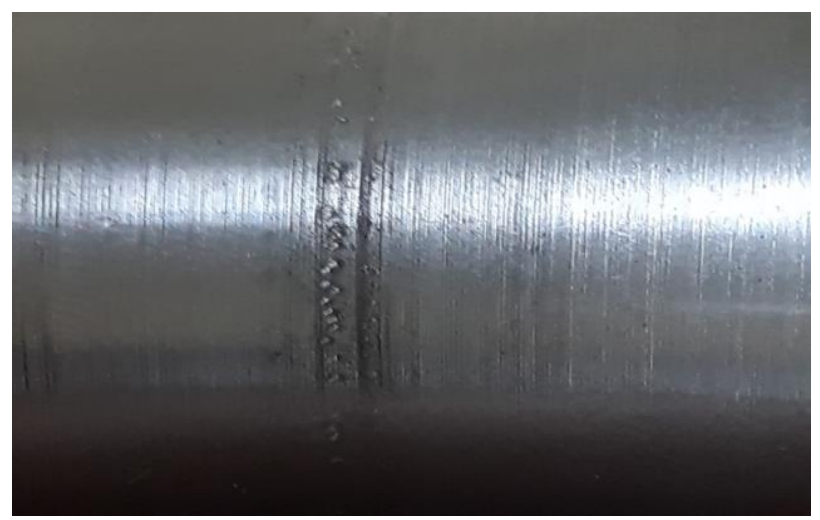

Şekil 4. SAE (AISI) 1040 çeliğinin 10000 noktasal temas sonucunda yüzey görünümü

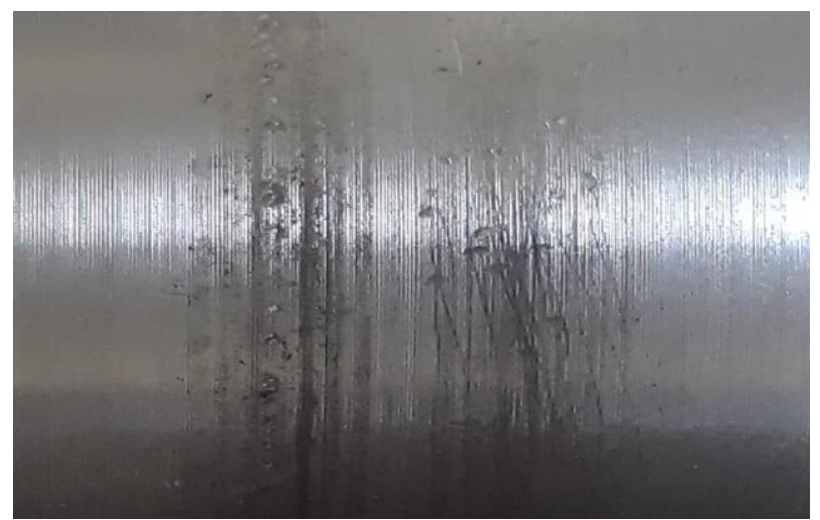

Şekil 5. SAE (AISI) 8620 çeliğinin 10000 noktasal temas sonucunda yüzey görünümü

\section{Tartışma ve Sonuç}

Çalışmasında, inşaat asansörleri istikamet makaraları imalatında farklı çelik malzemelerin kullanılmasının aşınma üzerine etkisi deneysel çalıșma ile saptanmaya çalıșılmıștır. SAE (AISI) 4140, SAE (AISI) 8620 ve SAE (AISI) 1040 çelikleri kullanılarak imal edilen 12 adet istikamet makarası test cihazında yağsız kuru sürtünme şartlarında aşınmaya maruz bırakılmıştır. Deneyde kullanılan istikamet makaralarının testleri $50,81 \mathrm{~N} / \mathrm{mm}^{2}$ yüzey gerilimi altında yapılmıştır. Bütün makaralar 2500, 5000, 7500 ve 10000 adet noktasal temasta çalıştırılmasından sonra, tartımdan önce yüzeydeki aşınma tozlarının olumsuz etkisine karşı metil alkol ile temizlenmiştir. Aşınma sonucu ortaya çıkan aşınma tozları fiziksel olarak, boyut ve șekil açısından incelenmiş olup, herhangi bir ölçüme gerek görülmemiştir. Hassas terazi yardımıyla tüm makaraların ağırlıkları 2500, 5000, 7500 ve 10000 adet noktasal temas sayısı için tartılmıştır ve aşağıdaki sonuçlara ulaşılmıştır:

- Birbirleri ile sürekli temas halindeki yüzeylerde, yüzeyin hemen altında bir çatlak oluşması ve çatlağın yüzeye kadar ilerlemesi ile bir parçanın kopması söz konusudur. Bu kopma ile karakterize edilen aşınma türü, yorulma aşınması olarak ifade edilmektedir. [10, 5]. Çalışmada kullanılan istikamet makaralarında aşınma mekanizması yorulma aşınması olarak tespit edilmiştir. Tunna vd. (2007) demiryollarında yaptığı çalışmada tekerlek üzerinde yorulma aşınması meydana geldiğini bulmuşlardır.

- Yaptığımız çalışmada, aşınma partiküllerinin kontrolü ve aşınan yüzeylerin incelenmesi neticesinde, aşınma mekanizması olarak yorulma aşınmasının meydana geldiği tespit edilmiştir.

- $\quad$ SAE (AISI) 4140 çeliğinden imal edilen istikamet makaralarının 2500, 5000, 7500 ve 10000 noktasal temasindan sonra meydana gelen aşınma ağırlık kaybı miktarı sırasıyla 0,01, 0,03, 0,09 ve 0,16 gr bulunmuştur.

- $\quad$ SAE (AISI) 8620 çeliğinden imal edilen istikamet makaralarının 2500, 5000, 7500 ve 10000 noktasal temasindan sonra meydana gelen aşınma ağırlık kaybı miktarı sırasıyla 0,07, 0,12, 0,21 ve 0,32 gr bulunmuştur.

- $\quad$ SAE (AISI) 1040 çeliğinden imal edilen istikamet makaralarının 2500, 5000, 7500 ve 10000 noktasal temasindan sonra meydana gelen așınma miktarı sırasıyla $0,02,0,05,0,13$ ve 0,19 gr bulunmuştur.

- Artan noktasal temas sayısı ile tüm istikamet makaralarındaki aşınma miktarlarında da artış görülmektedir.

- Sertlikleri birbirine çok yakın olmasına rağmen, bu sonuçlar göz önünde alındığında, aynı șartlar altında gerçekleştirilen deneylerde istikamet makaraları arasında aşınma ağırlık kaybı miktarı toplamı en fazla 0,72 gr ile SAE (AISI) 8620 çeliğinde görülmüştür. İkinci olarak 0,39 gr ile SAE (AISI) 1040 çeliği ve en az așınma miktarı 0,29 gr ile SAE (AISI) 4140 çeliğinde tespit edilmiştir. 
- Soydan vd. (2008) yapmış oldukları çalışmada, farklı çelikleri (SAE (AISI) 1050, SAE (AISI) 4140 ve SAE (AISI) 8620) aşınmaya maruz bırakmıșlardır. Bunun sonucunda sertlikleri aynı olmasına rağmen çok farklı aşınma miktarları bulmuşlardır. $\mathrm{Bu}$ sonucu da malzemelerin kimyasal uyumsuzluğuna bağlamışlardır [11].

SAE (AISI) 4140 çeliğinde 10000 noktasal temas sayısındaki aşınma miktarı 0,16 gram bulunmuştur. SAE (AISI) 8620 çeliğinde ise 10000 noktasal temas sayısındaki aşınma miktarı 0,32 gram bulunmuştur. SAE (AISI) 8620 çeliğinin \%Ni miktarı \%0,53'dür. SAE (AISI) 4140 çeliğinde \%Ni miktarı SAE (AISI) 8620 çeliğine göre düşük olup $\% 0,12$ dir. $\mathrm{Bu}$ durumda nikelin, tokluk üzerine etkisi pek fazla olmayıp, așınma dayanımını etkilememiștir. SAE (AISI) 4140 çeliğinde karbon ve krom miktarları sirasiyla $\% 0,43$ ve $\% 0,96$ olup SAE (AISI) 8620 çeliğinden daha yüksektir. Karbon ve kromun fazla olmasının aşınma direncini olumlu yönde etkilediği görülmüştür.

Pahalı çelik kullanım yerine, aynı görevi yapacak daha ucuz çelik malzeme kullanılabileceğinin gösterilebileceği, tezin amaçları içerisinde yer almıştır. Deneylerde kullanılan çelik çeşitleri için fiyat araştırması yapılmış olup SAE (AISI) 4140 çeliği ile SAE (AISI) 1040 çeliğinin kilogram fiyatları 7-8 TL arasında, SAE (AISI) 8620 çeliğinin ise kilogram fiyatının 11 TL civarında olduğu görülmüştür.

Sonuç olarak, inşaat asansörleri istikamet makaralarında, bu 3 farklı çelik malzemeden en az aşınma miktarına sahip ve fiyat açısından uygun olan SAE (AISI) 4140 çeliğinin kullanılmasının uygun olduğu görülmüştür. Bu sonuçtan hareketle, inşaat yük asansörlerinde periyodik kontrollerden önce istikamet makaralarının aşınmasının önüne geçilebilecek ve olası iş kazalarının önlenmiş olacağı düşünülmektedir.

\section{Teşekkür}

2210-C 2018/2 Yurt İçi Öncelikli Alanlar Yüksek Lisans Burs Programı kapsamında burs vererek maddi destek sağlayan Türkiye Bilimsel ve Teknolojik Araştırma Kurumu'na (TÜBITAK) teşekkür ederim.

\section{Kaynakça}

[1] Ünal, M. Ö., Aykaç, B. 2010. Yapı İşlerinde Asansör Kazaları ve Güvenlik Önlemleri. International Journal of Engineering Research and Development, 2(2), 13-19.

[2] Özmen, Y., Aksoy, T., Can, A. 1991. Așınmaya Etki Eden Faktörler ve Aşınmanın Azaltılması İçin Alınabilecek Tedbirler. 4. Denizli Malzeme Sempozyumu, Denizli, 651-663.

[3] Koraman, E. 2011. Al-Fe-V-Si Alaşımlarının Yüksek Sıcaklık Aşınma Özelliklerinin
İncelenmesi. İstanbul Teknik Üniversitesi, Fen Bilimleri Enstitüsü, Yüksek Lisans Tezi, 87 s, İstanbul.

[4] Şahin, S. Yorulma ve Aşınma. https://docplayer.biz.tr/12772304-Doc-drsalim-sahin-yorulma-ve-asinma.html. (Erişim Tarihi : 03.12.2019).

[5] Varol, T., 2016. Așınma Deneyi. Karadeniz Teknik Üniversitesi, Mühendislik Fakültesi, Metalurji ve Malzeme Mühendisliği Bölümü, Laboratuvar Föyü. Trabzon.

[6] Çöl, M. N. 2013. Si3N4 Ve CNT Nano Partiküllerin Yăg Katkısı Olarak AISI 4140 Çeliğinin Așınma Özelliklerine Etkisinin İncelenmesi. Eskişehir Osmangazi Üniversitesi, Fen Bilimleri Enstitüsü, Yüksek Lisans Tezi, 104 s, Eskişehir.

[7] Asil Çelik Sanayi ve Ticaret A.Ş., 2019. Kalite Belgesi/Quality certificate. Rapor no:103012, 1s.

[8] Asil Çelik Sanayi ve Ticaret A.Ş., 2019. Kalite Belgesi/Quality certificate. Rapor no:103243, 1s.

[9] Aydınlar Mak. Met. LTD. ŞTİ., 2016. Kalite Belgesi/Mill Test Certificate. Rapor no:83816 1s.

[10] Tunna, J., Sinclair, J., \& Perez, J. 2007. A Review of Wheel Wear and Rolling Contact Fatigue. Proceedings of the Institution of Mechanical Engineers, Part F: Journal of Rail and Rapid Transit, 221(2), 271-289.

[11] Soydan, Y., Köksal, S., Demirer, A., \& Çelik, V. 2008. Sliding Friction and Wear Behavior of Pack-Boronized AISI 1050, 4140, and 8620 Steels. Tribology Transactions, 51(1), 74-81. 